\title{
Avaliação do potencial de compostos naturais (argila, turfa e carvão) na remoção de chumbo e toxicidade de um efluente industrial
}

\author{
Evaluation of the potential of natural compounds (clay, peat and activated \\ carbon) for the removal of lead and toxicity of an industrial effluent
}

\section{Richard Clayton Tomasella', Edson Gomes de Oliveira ${ }^{2 \dagger}$, Dejanira de Franceschi de Angelis ${ }^{3}$, Marcelo Loureiro Garcia ${ }^{4}$}

\begin{abstract}
RESUMO
Métodos de tratamento avançado utilizando-se de materiais adsorventes alternativos podem substituir ou complementar tratamentos convencionais existentes, auxiliando na remoção de substâncias tóxicas provindas de diversos processos industriais. Espectrometria e testes biológicos (toxicidade aguda e crônica)auxiliam no monitoramento dos rejeitos industriais, avaliando a eficiência desses sistemas alternativos de tratamento de efluentes. O trabalho objetivou promover a redução da concentração do chumbo $(\mathrm{Pb})$ e da toxicidade de um efluente industrial utilizando o potencial de compostos naturais (argilominerais e turfa) e do carvão ativado (controle) como adsorventes em ensaios em batelada. O carvão ativado permitiu remover 99,4\% do Pb no efluente (15 min), e para os demais adsorventes a remoção ocorreu progressivamente até 24 horas, resultando em eficiências de remoção de 88,0\% (argila do Vale do Paraíba - VP), 73,6\% (argila de Ajapí - A) e 63,5\% (turfa). A toxicidade aguda foi completamente removida com a utilização do carvão ativado, enquanto eficiências de remoção maiores do que 50\% foram obtidas utilizando compostos naturais. Efeito tóxico significativo não foi observado após o tratamento com o carvão ativado e argila VP com relação à toxicidade crônica. Os resultados indicam a possibilidade de utilização da argila VP como adsorvente de baixo custo comercial em métodos de tratamento avançado.
\end{abstract}

Palavras-chave: despejo de efluentes, adsorventes argilominerais, polimento de efluentes.

\begin{abstract}
Advanced treatment methods using alternative adsorbent materials may replace or complement existing conventional treatments, aiding the removal of toxic substances coming from industrial processes. Spectrometry and biological tests (acute/chronic toxicity) aid the monitoring of industrial wastewater discharge, evaluating the effectiveness of these alternative systems of wastewater treatment. The study aimed to promote the reduction of lead $(\mathrm{Pb})$ and toxicity concentration of an industrial effluent using the potential of natural compounds (clay and peat) and activated carbon (control) as adsorbents in batch tests. The activated carbon allowed a removal efficiency of $99.4 \%$ of $\mathrm{Pb}$ in the effluent (15 min.), and for others the removal occurred progressively up to 24 hours, resulting in removal efficiencies of $88.0 \%$ (Vale do Paraiba clay - VP), 73.6\% (Ajapí clay - A) and 63.5\% (peat). The acute toxicity was completely removed using activated carbon, as removal efficiencies higher than 50\% were obtained using natural compounds. It was not observed significant toxic effect after the treatment with activated carbon and VP clay in relation to chronic toxicity. The results indicate the possibility of using VP clay as inexpensive commercial adsorbent in advanced treatment methods.
\end{abstract}

Keywords: wastewater discharge, mineral adsorbent, effluent polishing

\footnotetext{
Programa de Pós-Graduação em Geociências e Meio Ambiente doInstituto de Geociências e Ciências Exatas daUniversidade Estadual Paulista "Júlio de Mesquita Filho" (UNESP), Campus Rio Claro - Rio Claro (SP), Brasil.

2Departamento de Geologia Aplicada do Instituto de Geociências e Ciências Exatas da UNESP, Campus Rio Claro - Rio Claro (SP), Brasil. ${ }^{3}$ Departamento de Bioquímica e Microbiologia Aplicada dolnstituto de Biociências da UNESP, Campus Rio Claro - Rio Claro (SP), Brasil. ${ }^{4}$ Departamento de Petrologia e Metalogenia do Instituto de Geociências e Ciências Exatas da UNESP. Campus Rio Claro - Rio Claro (SP), Brasil. Endereço para correspondência: Marcelo Loureiro Garcia - Avenida 24-A, 1515 - Bela Vista - 13506-900 - Rio Claro (SP), Brasil - E-mail: mlgarcia@rc.unesp.br Recebido: 19/10/13 - Aceito: 22/10/14 - Reg. ABES: 125291
} 


\section{INTRODUÇÃO}

Nas últimas décadas, a elevada quantidade de efluentes descartados nos corpos hídricos, em razão do aumento das atividades industriais, tem contribuído para o agravamento de problemas ambientais, principalmente, em relação à preservação das águas superficiais e subterrâneas. Esses efluentes, na maioria das vezes, contêm metais tóxicos em suas composições e, quando lançados ao meio ambiente sem tratamento adequado, podem contaminar e poluir toda a estrutura e a dinâmica de um ecossistema. Esse processo pode afetar diretamente a biodiversidade dos seres vivos que a ele pertencem, podendo causar sérios problemas ecológicos e comprometendo a integridade fisiológica.

Atividades industriais que estão diretamente ligadas à utilização de metais potencialmente tóxicos em seus processos fabris podem ocasionar sérios problemas ambientais. Dependendo da forma físico-química como esses metais apresentam-se no efluente, podem estar biodisponíveis aos seres vivos e ao meio em que se encontram, proporcionando uma determinada toxicidade nas águas residuárias. Dentre os metais pesados potencialmente tóxicos, o chumbo é um dos mais preocupantes em razão de sua toxicidade e larga utilização (BUENO \& CARVALHO, 2007).

Quando ocorre contaminação no ambiente envolvendo íons metálicos, o tratamento convencional é realizado por processos físico-químicos como precipitação química, sedimentação e filtração. No entanto, esses tratamentos convencionais são inadequados para a descontaminação de grandes volumes de efluentes contendo íons metálicos potencialmente tóxicos em baixas concentrações devido à baixa eficiência operacional e aos elevados custos de extração resultante desse processo (NERBITT \& DAVIS, 1994).

Tendo em vista esse problema, alternativas estão sendo utilizadas para mitigar esses poluentes e contaminantes ambientais, com a finalidade de melhorar os processos finais de tratamento de efluentes. Entre elas, os tratamentos adicionais chamados de "polimento" podem ser necessários para enquadrar os efluentes à conformidade da legislação ambiental vigente dos países, uma vez que essas legislações estão cada vez mais exigentes e criteriosas quanto aos parâmetros físicos, químicos e biológicos referentes ao descarte de efluentes industriais (PSA, 2012).

Entre os tratamentos para remediação dos efluentes contaminados, pode-se citar a utilização das resinas sintéticas de troca catiônica. No entanto, em razão do elevado custo desses produtos, pesquisas envolvendo outros materiais de custos mais convenientes, amplamente disponíveis na natureza e utilizados praticamente sem processamento, estão sendo realizadas como forma de tratamentos alternativos para substituir ou complementar tratamentos convencionais já existentes (BUENO, 2007 apud PETRONI, 2000). Nesse contexto, muitos materiais naturais estão sendo testados como alternativas viáveis para o tratamento adequado dos efluentes gerados na produção industrial, entre eles os argilominerais, turfas orgânicas e carvões ativados (FENG et al., 2004).

A partir dos anos 1970, com os estudos mais avançados das propriedades dos argilominerais, as zeólitas artificiais começam a ser substituídas por argilas que funcionam como catalisadores naturais (LUNA \& SHUCHARDT, 1999). Em razão do baixo custo, da fácil obtenção e da possibilidade de reutilização, a aplicação dessas argilas com propriedades adsorventes está sendo difundida. Além disso, as propriedades adsortivas atuam como barreiras geoquímicas, proporcionando elevado potencial de remoção de metais pesados e substâncias tóxicas nos efluentes (ANDRADE, 1997; AGUIAR et al., 2002; MOREIRA, 2004; BLUMER \& OLIVEIRA, 2008).

As turfas vêm sendo estudadas como alternativa tecnológica de adsorvente natural de baixo custo, aplicada ao tratamento e à descontaminação de efluentes contaminados por metais pesados e outras substâncias tóxicas (D’AVILA et al.,1992; PETRONI, 1999).

Por outro lado, o carvão ativado, além de ser aplicado na purificação de águas residuais, é frequentemente utilizado na remoção de íons metálicos devido a sua grande área superficial e sua afinidade por compostos que contaminam e poluem o meio ambiente, como agrotóxicos, cianotoxinas, corantes orgânicos, além dos metais pesados, entre eles o chumbo (HAGER,1976; CHEN \& WU, 2004; YOUSSEF et al., 2003). O processo de remoção de composto inorgânico e material orgânico a partir da utilização de carvão ativado vem sendo amplamente empregado basicamente em indústria metalúrgica, alimentícia, química analítica e de tratamento de água e efluentes (ODA \& NAKAGAWA, 2003; LIMA et al., 2006).

Juntamente aos estudos de métodos alternativos para diminuir ou remover substâncias potencialmente tóxicas dos efluentes industriais, a utilização de métodos biológicos ajudam e auxiliam como parâmetros que fornecem dados relacionados à presença de toxicidade nos efluentes com perigo potencial para o meio ambiente e todo ser vivo, entre eles o homem. Além disso, testes ecotoxicológicos são utilizados com a finalidade de determinar a toxicidade aguda ou crônica por meio da utilização de microcrustáceos (CETESB,1987; WIECZOREK, 2003; ZAGATTO \& BERTOLETTI, 2006; RUBINGER, 2009). Esses testes são constantemente utilizados por agências ambientais no monitoramento dos rejeitos industriais para avaliar a eficiência de sistemas de tratamento de efluentes.

Por esses motivos, estudos relacionados à eficácia dos tratamentos de baixo custo na remoção de contaminantes e, consequentemente, na diminuição ou na eliminação da toxicidade têm sido realizados. Este trabalho objetivou a remoção do metal tóxico chumbo $(\mathrm{Pb})$ e da toxicidade de um efluente industrial de processamento de óxido de chumbo utilizando compostos naturais (argila de Ajapí (A), argila do Vale do Paraíba (VP) e turfa orgânica), comparados ao carvão ativado comercial.

\section{MATERIAL E MÉTODOS}

As amostras de efluentes foram oriundas de uma indústria química, contextualizada no Estado de São Paulo, que fabrica óxido de chumbo. O efluente gerado no processo de fabricação contém o metal pesado chumbo $(\mathrm{Pb})$ em baixa concentração, além de graxas e detergentes. 
Os adsorventes argila (A), argila (VP) e turfa foram coletados em campo. A argila (VP) foi obtida na área central da Bacia de Taubaté, São Paulo, da porção referente à Formação Tremembé. A argila apresenta uma coloração esverdeada contendo esmectitas, illitas e caulinitas (RICCOMINI et al., 2004). A argila (A) foi obtida na região de Rio Claro, São Paulo (distrito de Ajapí), pertencente à Formação Corumbataí, a qual é constituída por camadas, estratos e lâminas de argilitos, siltitos e arenitos. Do ponto de vista minerológico, o argilomineral dominante na área (mineração Tutte) é a montmorillonita, seguida da illita e caulinita (CHRISTOFOLETTI, 2003). A turfa utilizada no trabalho é oriunda da região de Conchal, São Paulo, nas proximidades do rio Mogi-Guaçu. As turfeiras da região estão relacionadas a um ambiente fluvial, ocorrendo na planície de inundação do rio Mogi ao longo da época holocênica. Essas turfeiras apresentam de 20 a 2.000 hectares e espessuras que variam de 1 a 3 metros de profundidade, podendo chegar a 8 metros em algumas áreas da bacia hidrográfica e em meandros abandonados. Em geral, essas turfas são fibrosas a hêmicas, com teor de cinza superior a 20\% (OLIVEIRA, 2002).

Algumas características fundamentais sobre a turfa, associadas ao fenômeno de adsorção, podem ser encontradas na literatura (COUILLARD, 1994; PETRONI, 2000; FRANCHI, 2004 apud STEVENSON, 1994).

O carvão em pó ativado foi adquirido comercialmente por meio do fornecedor Synth para fins comparativos. O efluente industrial foi coletado a uma temperatura de $25^{\circ} \mathrm{C}$ e resfriado em frascos hermeticamente fechados a uma temperatura de aproximadamente $4^{\circ} \mathrm{C}$ até a realização dos testes em batelada, físico-químicos e de toxicidade.

\section{Preparação das amostras, análises e procedimento experimental}

Primeiramente, as amostras de argila (A) e argila (VP) passaram por um processo de moagem, atingindo uma granulometria média de 2,5 a 5,0 $\mathrm{mm}$. Posteriormente, esse material foi moído, atingindo uma granulometria passante $100 \%$ na malha de $0,074 \mathrm{~mm}$ de diâmetro. A turfa retirada em campo estava destorroada. Em seguida, as argilas e a turfa foram secas a $60^{\circ} \mathrm{C}$ por um período de 24 horas, com o intuito de retirar a umidade. Após esse processo, as amostras foram peneiradas nas malhas de 0,297; 0,149 e 0,074 mm de diâmetro segundo classificação da Associação Brasileira de Normas Técnicas (ABNT). Utilizou-se a amostra passante na peneira de $0,074 \mathrm{~mm}$ para a realização do experimento (ensaio em batelada, difração raios-x e porosidade). A preparação das amostras foi realizada no Departamento de Petrologia e Metalogenia (DPM) da UNESP/Rio Claro, São Paulo.

As amostras peneiradas foram misturadas com água, e as misturas foram depositadas sobre lâminas de vidro jateado, formando uma delgada película sobre o vidro. Após o preparo das seções, estas foram deixadas em repouso até a película de argila ficar totalmente seca, para a realização da difração raios-X.A difração raios-x das argilas foi realizada no difratômetro da marca Siemens D5000. O ângulo $2 \theta$ de início foi de $3^{\circ}$ e de término foi de $67^{\circ}$, com passo de 1 segundo e tamanho do

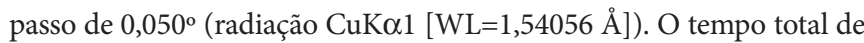
cada análise foi de 21'20", e a corrente empregada de $25 \mathrm{~mA}$ a uma voltagem de $35 \mathrm{kV}$. Imediatamente após a execução da difratometria nas amostras totais normais, a seção utilizada foi colocada em atmosfera de etilenoglicol por aproximadamente 48 horas, pelo fato de esse composto propiciar uma expansão do retículo cristalino, da ordem de 1 a $2 \AA$, dos minerais do grupo das esmectitas ou montmorillonita, de acordo com a sua composição ou tipo, possibilitando a detecção desse composto nas amostras. As análises foram realizadas no Departamento de Petrologia e Metalogenia (DPM), da UNESP/Rio Claro, São Paulo. Utilizou-se o software EVA 2.0 e X' PertHighscore Plus para interpretação dos resultados.

A porosidade do carvão, argila (VP), argila (A) e turfa basearam-se nas características físicas dos materiais, incluindo área superficial BET e o volume dos poros que foram medidos via adsorção de $\mathrm{N}_{2}$ (g) no analisador ASAP 2020 - Acelerated Surface Area ADN Porosimetry System Micromeritics a $77 \mathrm{~K}\left(-196^{\circ} \mathrm{C}\right)$ em nitrogênio líquido. As análises foram realizadas no Departamento de Mecânica da Universidade de São Paulo (USP)/São Carlos, São Paulo.

Os ensaios para avaliar a eficiência de remoção do chumbo $(\mathrm{Pb})$ no efluente industrial químico foram realizados por meio de ensaios em batelada. Consideraram-se parâmetros como o pH, o tempo de contato $(\mathrm{Tc})$, a temperatura $\left({ }^{\circ} \mathrm{C}\right)$, a quantidade de material adsorvente (\%), a agitação em rotação por minuto (rpm) e a concentração de chumbo (mg..-1) na amostra bruta. Os experimentos ocorreram no Laboratório de Bioquímica e Microbiologia Aplicada da UNESP/Rio Claro, São Paulo, da seguinte maneira: Primeiramente, pesou-se $1 \mathrm{~g}$ de cada composto em balança analítica de alta precisão. Colocou-se cada composto em frascos erlenmeyer e foi adicionado $100 \mathrm{~mL}$ de efluente industrial em cada frasco ( $1 \%$ de composto nos frascos com o efluente). Foram preparadas combinações ( $1 \mathrm{~g}$ composto/ $100 \mathrm{~mL}$ efluente) para cada intervalo de tempo $(1 / 4 \mathrm{~h} ; 1 / 2 \mathrm{~h} ; 1 \mathrm{~h} ; 3 \mathrm{~h} ; 8 \mathrm{~h} \mathrm{e}$ $24 \mathrm{~h}$ ). Posteriormente, vedaram-se os frascos e agitou-se a $200 \mathrm{rpm}$ em shaker (Ma 410/E - Marconi) a uma temperatura controlada de $25^{\circ} \mathrm{C}$.

Após o sistema em batelada, o sobrenadante foi filtrado em filtro 0,45 microns e foi feita análise de Unidade Nefelométrica de Turbidez (UNT) do efluente tratado e a quantificação do elemento chumbo $(\mathrm{Pb})$ segundo os Standard Methods (APHA, 2005). O metal das amostras foi analisado no Centro de Estudos Ambientais (CEA) da UNESP/Rio Claro, São Paulo, mediante a utilização do equipamento de Espectrometria de Emissão Óptica com Fonte de Plasma de Argônio Indutivo (ICP-OES).

A realização do teste de toxicidade aguda ocorreu segundo os procedimentos da ABNT (2009). Os resultados em CE(50) foram obtidos mediante o programa estatístico Spearman-Karber. O teste de toxicidade crônica foi realizado conforme a ABNT (2011). Os resultados em CENO foram analisados pelo programa estatístico TOXSTAT 3.5, no qual foram observadas a mortalidade (Prova exata de Fischer) e a natalidade dos indivíduos (Teste de Qui-Quadrado; Teste de Bartlett e 
Teste de Williams). O resumo dos testes de toxicidade aguda e crônica é apresentado na Tabela 1.

\section{RESULTADOS E DISCUSSÃO}

\section{Características físico-químicas dos adsorventes}

$\mathrm{O}$ argilomineral montmorillonita (Mnt) e o quartzo (Qtz) foram predominantemente detectados na amostra de argila $\mathrm{A}$, segundo análise de difração raios-x (Figura 1a), enquanto na amostra de argila VP (Figura 1b) detectou-se predominantemente os argilominerais caulinita (Kln) e illita (Ill). A presença de argilominerais em ambas as amostras pode favorecer a remoção de substâncias iônicas contidas no efluente.

Em relação às propriedades físicas, foi estabelecida uma correlação entre a superfície de resposta e a estrutura física desses compostos mediante a técnica de porosimetria de adsorção de nitrogênio. A partir dessa correlação, obteve-se a área superficial BET, em $\mathrm{m}^{2} \cdot \mathrm{g}^{-1}$, de 662,6 (carvão), 106,6 (argila VP), 36,6 (argila A) e 19,2 (turfa). $\mathrm{O}$ volume de poros no processo de adsorção do nitrogênio também foi avaliado, obtendo-se um volume, em $\mathrm{cm}^{3}$. $\mathrm{g}^{-1}$, de 0,25 (carvão), 0,19 ( $\operatorname{argila~VP),~0,15~(argila~A)~e~0,10~(turfa).~A~análise~de~porosimetria~}$ com nitrogênio auxilia a escolha de compostos potenciais para estudos de remoção de constituintes na operação unitária de adsorção, de acordo com as propriedades físicas dos materiais.

O carvão ativado é um material carbonáceo com porosidade bastante desenvolvida, que, ao sofrer processamento, aumenta a porosidade interna. A área superficial da maioria dos materiais carbonáceos pode variar entre 10 e $15 \mathrm{~m}^{2} \cdot \mathrm{g}^{-1}$ (CLAUDINO \& MINOZZO, 2000). A partir da ativação desses materiais, em especial os carvões podem apresentar uma área superficial entre $450 \mathrm{e} 1.500 \mathrm{~m}^{2} \cdot \mathrm{g}^{-1}$. Em relação ao volume de poros de um carvão ativado, pode apresentar valores entre 0,5 e $1,5 \mathrm{~cm}^{3} \cdot \mathrm{g}^{-1}$ (BANSAL \& GOYAL, 2005; SLEJKO, 1985). A avaliação do desempenho do processo, apresentada a seguir, objetivando a proposição de compostos naturais como adsorventes, é realizada utilizando-se o carvão ativado como controle (padrão referencial), uma vez que este tem sua utilização consolidada em aplicações práticas.

\section{Avaliação do desempenho do processo}

A partir de ensaios em batelada, foi obtido o potencial de remoção do chumbo presente no efluente industrial pelos materiais adsorventes.
Tendo como finalidade comparar o melhor resultado obtido para os compostos naturais sem tratamento químico (argila A, argila VP e turfa) com o carvão ativado, foi analisado o tempo de contato desses compostos e do carvão (Figura 2 e Tabela 2).

Os resultados demonstram, ao carvão ativado, um equilíbrio adsortivo logo no início do sistema em batelada (15 minutos) até o término do experimento (24 horas). Com remoção de aproximadamente $100 \%$ do chumbo pelo carvão ativado, supõe-se que praticamente todas as espécies de chumbo dissolvidos no efluente interagiram rapidamente com sítios ativos disponíveis na superfície do carvão.

Em relação aos demais compostos esse equilíbrio adsortivo não é observado até o término do experimento (24 horas). Porém, para a argila VP, praticamente, $60 \%$ do chumbo disponível foi adsorvido logo no início do experimento. Esse fenômeno pode ter ocorrido devido às propriedades físico-químicas dos materiais adsorventes. De fato, observou-se uma proporcionalidade entre o desempenho de remoção de constituintes e as características físicas dos adsorventes. Considerando-se somente as características químicas dos materiais, a argila A apresentaria as melhores eficiências de remoção por conter o argilomineral expansivo montmorillonita.

Segundo a Resolução CONAMA n 430/2011 (BRASIL, 2011), o limite permissível de lançamento do efluente para o elemento chumbo total é de $0,5 \mathrm{mg} \cdot \mathrm{L}^{-1}$. Verifica-se que com o tratamento do efluente industrial com o carvão ativado em um curto período a concentração de lançamento se encontra dentro da normalidade, inclusive para os padrões de potabilidade (Portaria no 2.914/2011, BRASIL, 2011a). Por outro lado, em relação ao composto natural mais eficiente (argila VP), o efluente industrial se enquadra nos limites permissíveis de lançamento para o elemento chumbo, a partir dos 30 minutos de contato (Figura 2).

Além dos dados da remoção, verificou-se a taxa inicial de remoção e a densidade de adsorção do chumbo dos efluentes industrial. Ambos são parâmetros que podem ser utilizados como dados iniciais de um projeto em escala industrial, permitindo, dessa maneira, quantificar o conteúdo necessário desses compostos naturais e do carvão ativado para a remoção de certas substâncias no efluente. Além disso, avaliar o tempo necessário para que essa remoção aconteça também é fundamental para a realização desse projeto em larga escala.

A taxa inicial de remoção foi avaliada mediante a velocidade e a quantidade com que o adsorbato contido no efluente é adsorvido pelos sítios ativos do material adsorvente. Para o carvão ativado, a taxa

Tabela 1 - Comparação entre métodos na avaliação toxicológica de efluentes industrias.

\begin{tabular}{l|c|c|c|c}
\hline Organismo teste & Tipo & Duração & Variável de resposta & Resultados \\
Microcrustáceos - Daphnia sp & Agudo & $48 \mathrm{~h}$ & Mobilidade em 24 h e 48 h & CE(50) \\
\hline & Agudo & $48 \mathrm{~h}$ & Imobilidade de $50 \%$ ao término de 48 h & CE(50) \\
\hline Microcrustáceos - Ceriodaphnia sp & Crônico & 7 dias & Número de prole paternogênica, sobrevivência de fêmeas adultas & CENO \\
\hline
\end{tabular}

CE(50): concentração do efluente que causa efeito agudo (imobilidade) a 50\% dos organismos aquáticos em determinado período de exposição, em \%. CENO: concentração do efluente que não causa efeito crônico observável em determinado período de exposição, em \%. 


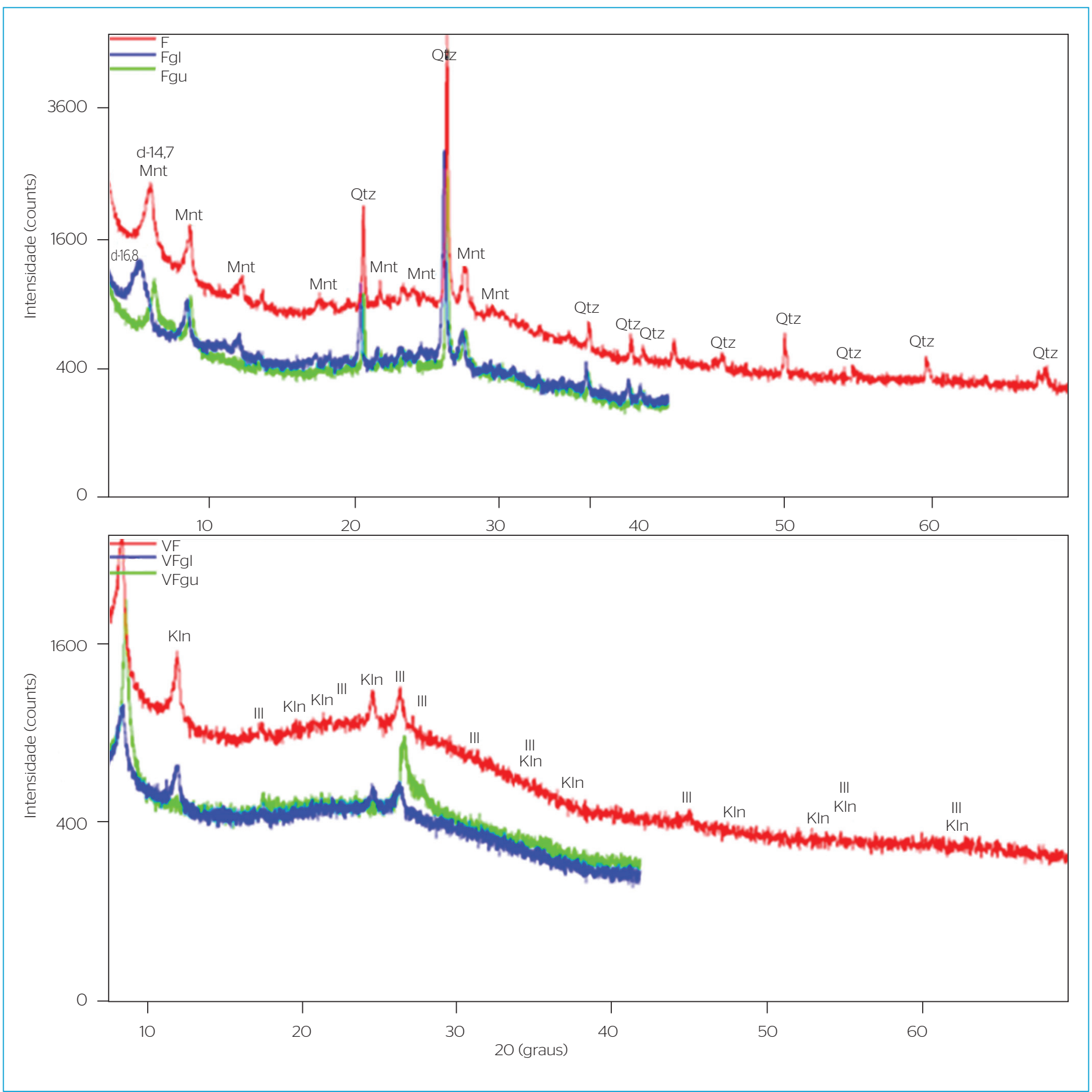

Figura 1 - Difratogramas da argila A (A) e VP (B), com amostras totais (em vermelho, 1a série), amostras tratadas com etilenoglicol (em azul, $2^{\mathrm{a}}$ série) e pós-queima (em verde, $3^{a}$ série). Os principais argilominerais montmorillonita (Mnt) e o quartzo (Qtz) foram detectados na amostra de argila A. Os argilominerais caulinita (KIn) e illita (III) foram detectados na amostra de argila VP.

inicial de remoção do chumbo foi de $0,11 \mathrm{mg} \cdot \mathrm{L}^{-1} \cdot \mathrm{min}^{-1}$, enquanto para o melhor composto natural, a argila VP, a taxa foi de $0,07 \mathrm{mg} \cdot \mathrm{L}^{-1} \cdot \mathrm{min}^{-1}$.

Em relação à densidade de adsorção do chumbo, ou seja, a concentração do chumbo (mg.L-1) retido por grama (g) de cada composto, obteve-se para o carvão ativado uma densidade de adsorção inicial de $0,166 \mathrm{mg}(\mathrm{Pb}) \cdot \mathrm{g}^{-1}$, enquanto para o composto mais eficiente, a argila VP, essa densidade foi de $0,123 \mathrm{mg}(\mathrm{Pb}) \cdot \mathrm{g}^{-1}$. Valores mais elevados de densidades de adsorção iniciais e taxas de remoção iniciais de chumbo $\left(0,242 \mathrm{mg} \cdot \mathrm{g}^{-1}\right.$ e $0,16 \mathrm{mg} \cdot \mathrm{L}^{-1} \cdot \mathrm{min}^{-1}$, respectivamente $)$ foram obtidos para os três adsorventes - carvão ativado, argila VP e argila $\mathrm{A}-$, nos ensaios com efluente sintético contendo apenas o elemento chumbo (dados não mostrados), indicando a influência da presença de outros materiais orgânicos e inorgânicos do efluente industrial complexo no desempenho de tratamento e a viabilidade de utilização 
dos argilominerais como adsorventes para efluentes industriais de composição simples. Nesse caso, admitindo-se a ocorrência de interferências e a similitude dos valores dos parâmetros de desempenho do processo com o efluente sintético, as características químicas podem passar a ter relevância na própria eficiência de remoção de constituintes. Os argilominerais expansivos apresentam propriedades específicas, de modo que nem todos os sítios ativos estão prontamente disponíveis na

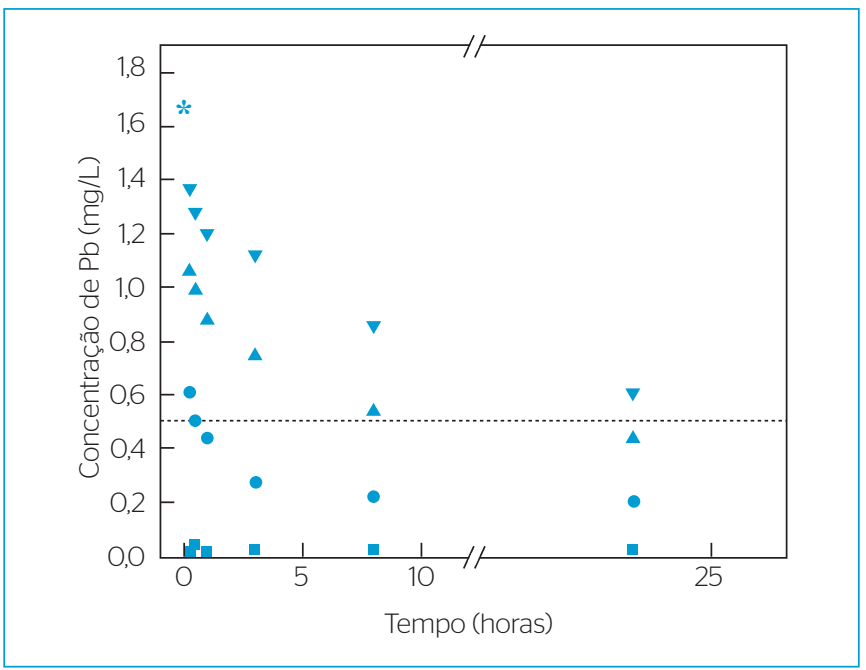

Figura 2 - Concentração residual de chumbo (mg.L-1) do efluente industrial por tempo de contato. Legenda: carvão ativado ( $\square$ ), argila VP $(\bullet)$, argila $A(\boldsymbol{\Delta})$ e turfa $(\boldsymbol{\nabla})$. A linha tracejada indica o limite permissível de lançamento para o elemento chumbo, conforme a Resolução CONAMA $n^{\circ}$ 430/2011.

Tabela 2 - Remoção do chumbo (\%) do efluente mediante o tempo de contato.

\begin{tabular}{l|c|c|c|c|c|c|c} 
& $\mathrm{O} \mathbf{h}$ & $1 / 4 \mathrm{~h}$ & $1 / 2 \mathrm{~h}$ & $1 \mathrm{~h}$ & $3 \mathrm{~h}$ & $\mathbf{8} \mathrm{h}$ & $24 \mathrm{~h}$ \\
\hline Carvão ativado & $\mathrm{O}$ & 99,4 & 97,6 & 98,8 & 98,2 & 98,8 & 99,4 \\
\hline Argila VP & 0 & 63,5 & 70,0 & 73,6 & 83,8 & 86,8 & 88,0 \\
\hline Argila A & 0 & 36,5 & 40,7 & 47,3 & 55,1 & 67,7 & 73,6 \\
\hline Turfa & 0 & 18,0 & 23,4 & 28,1 & 32,9 & 48,5 & 63,5 \\
\hline
\end{tabular}

Batelada: 1\%; 25ํ; Agitação: 200 rpm.

Tabela 3 - Análise da turbidez e pH do efluente após o tratamento com os compostos.

\begin{tabular}{|l|l|l|l|l|l|}
\hline Amostra & Efluente & Turfa & Argila A & Argila VP & Carvão ativado \\
\hline
\end{tabular}

\begin{tabular}{l|c|c|c|c|c|c}
\hline Turbidez (UNT) & 11 & 19 & 10 & 6 & 6 \\
\hline $\mathrm{pH}$ & 8,30 & 7,88 & 8,29 & 8,17 & 9,05 \\
\hline
\end{tabular}

Batelada: 1\%; 25ㄷ; Tc: 3 horas; Agitação: 200 rpm.

Tabela 4 - Remoção e avaliação de toxicidade aguda utilizando Daphnia similis.

\begin{tabular}{l|c|c|c|c}
\hline Solução & $\mathrm{pH}$ & $\mathrm{CE}(50)$ & UT & Remoção (\%) \\
\hline Efluente bruto & 8,3 & 35,88 & 2,79 & - \\
\hline Argila VP & 8,17 & 79,46 & 1,25 & 55,2 \\
\hline Argila A & 8,29 & 85,82 & 1,16 & 58,4 \\
\hline Turfa & 7,88 & 84,54 & 1,18 & 57,7 \\
\hline Carvão ativado & 9,05 & NT & NT & 100,0 \\
\hline
\end{tabular}

NT: Não Tóxico; UT: Unidade Tóxica; CE(50): concentração do efluente que causa efeito agudo a 50\% dos organismos em determinado período de exposição, em \%. superfície externa das camadas, mas também entre as intercamadas do argilomineral. Esse fenômeno permite às argilas propriedades que as diferenciam de outros materiais naturais ou mesmo materiais sintetizados (VIERA-COELHO, 1991).

Além da remoção do chumbo, foram analisados outros parâmetros relacionados ao tratamento dos efluentes com os compostos naturais e o carvão ativado. Esses parâmetros são apresentados na Tabela 3.

Em relação à turbidez, a maior restrição refere-se ao corpo receptor de água doce - classe I, com limite de 40 UNT. Nesse caso, o efluente industrial analisado enquadrava-se nos parâmetros estabelecidos pela CONAMA n 357/2005 (BRASIL, 2005). Verificou-se que a argila VP e o carvão ativado são ótimos clarificadores de efluentes, enquanto a turfa utilizada nesse experimento deixa o efluente ligeiramente mais turvo. $\mathrm{O}$ pH analisado antes e após o tratamento do efluente industrial também se manteve dentro dos padrões estabelecidos na CONAMA $n^{\circ}$ 430/2011 e CONAMA no 357/2005, respectivamente.

Mais estudos fazem-se necessários para a compreensão do fenômeno, principalmente no que se refere à interferência da presença de outros constituintes no efluente e à influência do pH nas eficiências de remoção e/ou na manutenção das propriedades dos compostos naturais.

Os ensaios biológicos de toxicidade basearam-se no tempo de contato $(3 \mathrm{~h})$, composto $(1 \mathrm{~g})$, efluente $(100 \mathrm{~mL})$, concentração inicial de chumbo $\left(1,67 \mathrm{mg} \cdot \mathrm{L}^{-1}\right)$, temperatura $\left(25^{\circ} \mathrm{C}\right)$ e agitação $(200 \mathrm{rpm})$. Primeiramente, avaliou-se a toxicidade aguda e, a partir dos resultados obtidos, avaliou-se a toxicidade crônica para fins conclusivos referentes a cada fase, ou seja, a aguda e a crônica.

Os resultados em CE(50) e Unidade Tóxica (UT) e a remoção (em porcentagem) obtida com o teste de toxicidade aguda utilizando o microcrustáceo Daphnia similis, mediante o tratamento com os compostos, são apresentados na Tabela 4 .

Os testes foram realizados conforme ABNT (2009). Todos os compostos apresentaram eficiência na remoção, sendo o carvão ativado mais eficiente no tratamento, com remoção de $100 \%$ da carga tóxica do efluente, e para os demais compostos naturais a remoção da toxicidade foi acima de $50 \%$ da carga tóxica do efluente industrial.

Comparou-se o carvão ativado com o composto natural mais eficiente na remoção chumbo, uma vez que houve uma proximidade de remoção da toxicidade aguda para todos os compostos naturais. Os resultados em CENO, VC e CEO obtidos com o teste de toxicidade crônica utilizando o microcrustáceo Ceriodaphnia dubia e as consequentes remoções de toxicidade obtidas (em porcentagem) mediante o tratamento com os compostos são apresentados na Tabela 5.

Em relação à toxicidade crônica, o efluente bruto apresentou CENO de 6,25\%, ou seja, essa é a maior concentração de agente tóxico (efluente) que não causa efeito deletério estatisticamente significativo nos organismos no tempo de exposição e nas condições de teste. Acima dessa concentração, pode até permitir a sobrevivência dos organismos, mas 
Tabela 5 - Remoção e avaliação de toxicidade crônica utilizando Ceriodaphnia dubia.

\begin{tabular}{l|c|c|c|c|c}
\hline Solução & pH & CENO (\%) & VC(\%) & CEO (\%) & Remoção (\%) \\
\hline Efluente bruto & 7,16 & 6,25 & 8,84 & 12,5 & - \\
\hline Argila VP & 8,17 & NT & NT & NT & 100 \\
\hline Carvão ativado & 9,0 & NT & NT & NT & 100 \\
\hline
\end{tabular}

NT: Não Tóxico; CENO: Concentração do Efluente que Não causa Efeito crônico Observável em determinado período de exposição, em \%; VC: Valor Crítico; CEO: Concentração de Efeito Observado.

afetaria suas funções biológicas, como reprodução, desenvolvimento de ovos, crescimento e maturação, entre outras. Para os ensaios utilizando o carvão ativado e a argila VP, não houve diferenças estatisticamente significativas entre as diluições utilizadas. Em outras palavras, mesmo utilizando-se $100 \%$ de efluente tratado, nenhuma toxicidade foi verificada durante o período de teste.

\section{CONCLUSÕES}

Esse trabalho possibilitou a comparação do desempenho entre os compostos naturais e o carvão ativado na operação unitária de adsorção, permitindo, dessa maneira, escolher qual material seria o mais indicado para o tratamento do efluente em estudo. Resumidamente, a eficiência dos compostos na remoção do elemento chumbo ao término do experimento ocorreu na seguinte ordem: carvão ativado $(99,4 \%)$ $>$ argila VP $(88 \%)>$ argila A $(73,6 \%)>$ turfa orgânica $(63,5 \%)$. Além disso, obtiveram-se resultados positivos e expressivos na remoção da toxicidade aguda, utilizando o microcrustáceo Daphnia similis, para todos os compostos, tendo a eficiência dos compostos na remoção da toxicidade aguda ocorrido na seguinte ordem: carvão ativado (100\%)
> argila A (58,4\%) > turfa orgânica $(57,7 \%)>$ argila VP $(55,2 \%)$; e, em relação à toxicidade crônica, enquanto o efluente bruto apresentou uma CENO de apenas 6,25\%, não foi observado efeito significativo de toxicidade após o tratamento com o carvão ativado e com a argila VP. A partir do tratamento utilizando-se os argilominerais, com destaque à argila VP e o carvão ativado, permitiu-se adequar o efluente industrial aos parâmetros de lançamento, conforme as legislações pertinentes, especialmente relacionados ao elemento chumbo. Esse processo de "polimento" com compostos naturais indica uma nova opção de tratamento e gerenciamento para os efluentes industriais após tratamentos convencionais.

\section{AGRADECIMENTOS}

Os autores agradecem à Coordenação de Aperfeiçoamento de Pessoal de Nível Superior (CAPES) pela concessão de bolsa de estudos; à Fundação para o Desenvolvimento da UNESP (FUNDUNESP) pelo auxílio financeiro ao desenvolvimento do projeto de pesquisa; à Fundação de Amparo à Pesquisa do Estado de São Paulo (FAPESP) e ao Conselho Nacional de Desenvolvimento Científico e Tecnológico (CNPq) por auxílio financeiro complementar. Agradecem também aos funcionários do Departamento de Bioquímica e Microbiologia Aplicada (IB/UNESP), do Centro de Estudos Ambientais (CEA/UNESP), do Departamento de Geologia Aplicada (DGA/IGCE/UNESP), do Departamento de Petrologia e Metalogenia (DPM/IGCE/UNESP) e do Departamento de Mecânica (EESC/USP) pelo auxílio na realização dos procedimentos experimentais e no fornecimento de local adequado para o desenvolvimento da pesquisa.

\section{REFERÊNCIAS}

ASSOCIAÇÃO BRASILEIRA DE NORMAS TÉCNICAS (ABNT). (2009) Ecotoxicologia aquática - Toxicidade aguda - Método de ensaio com Daphniaspp (Crustacea, Cladocera). Rio de Janeiro, 23p.

ASSOCIAÇÃO BRASILEIRA DE NORMAS TÉCNICAS (ABNT). (2O11) Ecotoxicologia aquática - Toxicidade crônica - Método de ensaio com Ceriodaphnia spp. (Crustacea, Cladocera). Rio de Janeiro, 18p.

AGUIAR, M.R.M.P.; NOVAES, A.C.; GUARINO, A.W.S. (2002) Remoção de metais pesados de efluentes industriais por aluminossilicatos. Química Nova, São Paulo, v.25, n.6b, dez.. Disponível em: <http://www.scielo.br/ scielo.php?script=sci_arttext\&pid=S010040422002000700015\&lng=e n\&nrm=iso>.Acesso em: 26 set. 2012.

AMERICAN PUBLIC HEALTH ASSOCIATION (APHA). (2005) Standard Methods for the Examination of Water and Wastewater 215t. Washington DC: APHA; AWWA; WEF.
ANDRADE, R.C.S. (1997) Remoção de Cr (VI) de soluções aquosas utilizando argilas aniônicas tipo hidrotalcita. 14Of. Dissertação (Mestrado em Engenharia Química) - Faculdade de Engenharia Química, Universidade Estadual de Campinas, Campinas.

BANSAL, R.C. \& GOYAL, M. (2005) Activated carbon adsorption. Flórida, USA: Taylor e Francis Group - Boca Raton.

BLUMER, A.C. \& OLIVEIRA, E.G. (2008) Remoção de cromo de resíduos de curtumes por argilitos da Formação Corumbataí - Rio Claro - SP. 41p. Trabalho de conclusão de curso (Graduação em Engenharia Ambiental) - IGCE, Universidade Estadual Paulista, Rio Claro, São Paulo.

BRASIL. (2005) Resolução CONAMA no 357. Dispõe sobre a classificação dos corpos de água e diretrizes ambientais para o seu enquadramento bem como estabelece as condições e padrões de lançamento de efluentes, e dá outras providências. Publicação DOU de 18/03/2005, p.58-63. 
BRASIL. (2011) Resolução CONAMA no 430/2011. Dispõe sobre condições e padrões de lançamento de efluentes, complementa e altera a Resolução n 357, de 17 de março de 2005, do Conselho Nacional do Meio Ambiente - CONAMA. Publicação DOU n.92, de 16/05/2011, 89p

BRASIL. (2011a) Portaria MS no 2914.Dispõe sobre os procedimentos de controle e de vigilância da qualidade da água para consumo humano e seu padrão de potabilidade. Publicação DOU de 14/12/2011.

BUENO C.I.C. \& CARVALHO W.A. (2007) Remoção de chumbo (II) em sistemas descontínuos por carvões ativados com ácido fosfórico e com vapor. Faculdade de Química, Centro de Ciências Exatas, Ambientais e de Tecnologias, Pontifícia Universidade Católica de Campinas, Campinas - SP, Brasil, Química Nova, v.30, n.8, p.1911-1918.

CHEN, J.P. \& WU, S. (2004) Simultaneous adsorption of copper ions and humic acid onto an activated carbon. Journal of Colloidand Interface Science, v.280, n.2, p.334-342

CHRISTOFOLETTI, S.R. (2003) Um modelo de classificação geológicotecnológico das argilas da Formação Corumbataí utilizadas nas indústrias do Pólo Cerâmico de Santa Gertrudes.186p. Tese (Doutorado em Geologia Regional) - IGCE, Universidade Estadual Paulista, Rio Claro, São Paulo.

CLAUDINO, A. \& MINOZZO, A.P. (2000) Projeto de uma indústria de carvão ativado. Trabalho referente à disciplina de Projetos. Universidade Estadual do Oeste do Paraná, p.6-7.

COMPANHIA AMBIENTAL DO ESTADO DE SÃO PAULO (CETESB). (1987) Avaliação da toxicidade de despejos industriais na região da grande São Paulo. CETESB, São Paulo, 2p.

COUILLARD, D. (1994) “Peat”. Water Research, v.28, n.12, p.61-70.

D’AVILA, J.S.; MATOS, C.M.; CAVALCANTI, M.R. (1992) Heavy Metals Removal from Wastewater by Using Activated Peat. Water Science Technology, v.26, n.9-11 p.2309-2312

FENG, Q.; LIN, Q.; CONG, F.; SUGITA, S.; SHOYA, M. (2004) Adsorption of lead and mercury by rice husk ash. Journal of Colloid and Interface Science, v.278, n.1, p.1-8.

GREGG, S.J. \& SING, K.S.W. (1997) Adsorption, surface area and porosity. 2ed. London: Academic Press.

HAGER, D.G. (1976) Waste water treatment via activated carbon. Pittsburgh: Calgon Corporation.

LIMA, A.J.B.; CARDOSO, M.G.; GUERREIRO, M.C.; PIMENTEL, F.A. (2006) Emprego do carvão ativado para remoção de cobre em cachaça. Química Nova, São Paulo, v.29, n.2, p.247-250.

LUNA, F.J. \& SCHUCHARDT, U. (1999) Argilas pilarizadas: uma introdução. Química Nova, São Paulo, v.22, n.1.

MOREIRA, C.S. (2004) Adsorção competitiva de cádmio, cobre, níquel e zinco em solos. 108f. Dissertação (Mestrado em Agronomia) - Escola Superior de Agricultura "Luiz de Queiroz", Universidade de São Paulo, Piracicaba, São Paulo.
NERBITT, C.C. \& DAVIS, T.E. (1994) Extraction and processing for the treatment and minimization of waste. San Francisco: Ed. The Mineral, Metals and Materials Society.

ODA, H. \& NAKAGAWA, Y. (2003) Removal of ionic substances from dilute solution using activated carbon electrodes. Carbon, v.41, p.1037-1047.

OLIVEIRA, C.A. (2002) Turfa de São José dos Campos: Estado de São Paulo. São Paulo: CPRM/MME, Superintendência Regional de São Paulo.

PETRONI, S.L.G. (1999) Adsorção de zinco e cádmio em colunas de turfa: potencialidade de utilização de um bioadsorvedor natural em sistemas de tratamento de efluentes. 99f. Dissertação (Mestrado) IPEN, Universidade de São Paulo, São Paulo.

PETRONI, S.L.G.; PIRES, M.A.F.; MUNITA, C.S. (2000) Adsorção de zinco e cádmio em colunas de turfa. Química Nova, São Paulo, v.23, n.4, p.447-481

PLANO DE SEGURANÇA DA ÁGUA (PSA). (2012) Garantindo a qualidade e promovendo a saúde - Um olhar do SUS/Ministério da Saúde, Conselho Nacional de Saúde. Brasília: Editora do Ministério da Saúde. 60p.

RICCOMINI, C.; SANT'ANNA, L.G.; FERRARI, A.L. (2004) Evolução Geológica do Rift Continental do Sudeste do Brasil. In: MANTESONETO, V.; BARTORELLI, A.; CARNEIRO, C.D.R.; NEVES, B.B.B. Geologia do Continente Sul-Americano: Evolução da Obra de Fernando Marques de Almeida. São Paulo: Beca. p.384-405

RUBINGER, C.F. (2009) Seleção de métodos biológicos para avaliação toxicológica de e fluentes industriais. 90 f. Dissertação (Mestrado em Engenharia Sanitária e Ambiental) - Universidade Federal de Minas Gerais, Departamento de Engenharia Hidráulica e Recursos Hídricos, Belo Horizonte.

SLEJKO, F.L. (1985) Adsorption Technology: A Step-by-Step Approach to Process Evaluation and Application. New York: Marcel Dekker Inc.

STEVENSON, F.J. (1994) Humus chemistry - genesis, composition, reactions. 2 ed. New York: John Wiley \& Sons.496p.

VIERA-COELHO, A.C. (1991) Caracterization d'argiles nickelifers du Brésil et etude du pontage de cesar giles et d'une mont morillonite par dês solutions hidroxy galliques et/ou aluminiques. Tese (Doutoramento) U. C. de Louvain-la-Neuve, Bélgica.

YOUSSEF, A.M.; EL-NABARAWY, T.H.; SAMRA, S.E. (2003) Sorption properties of chemically-activated carbons. Sorption of cadmium (II) ions. Colloids and Surfaces A: Physicochem. Eng. Aspects, v.235, n.1-3, p.153-163.

WIECZOREK, A. (2003) Efeito do efluente da refinaria de petróleo REPLAN/PETROBRAS sobre a dinâmica populacional de Daphnia similis. 81 p. Trabalho de conclusão de curso (Especialização em Ecotoxicologia Aquática) - IB. Universidade Estadual Paulista "Júlio de Mesquita Filho" - UNESP, Rio Claro, São Paulo.

ZAGATTO, P.A. \& BERTOLETTI, E. (2006) Ecotoxicologia Aquática: Princípios e Aplicações. São Carlos: Ed. RIMA. 478p. 